\title{
Metode Kerja Berorientasi Ergonomi pada Proses Pengelapan Kaleng Sarden Menurunkan Keluhan Muskuloskeletal dan Kelelahan Pekerja di PT. BMP Negara, Bali
}

\author{
Ni Luh Gede Aris Maytadewi Negara ${ }^{1}$, I Dewa Putu Sutjana ${ }^{2}$, dan Luh Made Indah Sri \\ Handari Adiputra ${ }^{3}$ \\ ${ }^{1}$ Program Studi Kesehatan dan Keselamatan Kerja, Institut Ilmu Kesehatan Medika Persada Bali, \\ ${ }^{2}$ Departemen Ilmu Faal, Fakultas Kedokteran, Universitas Udayana, ${ }^{3}$ Program Studi Magister \\ Ergonomi Fisiologi Kerja, Pascasarjana, Universitas Udayana \\ mayta.negara@gmail.com \\ doi: https://doi.org/10.24843/JEI.2019.v05.i01.p03
}

Article Received: 13 Mei 2019; Accepted: 10 Juni 2019; Published: 30 Juni 2019

\begin{abstract}
Abstrak
Kegiatan industri berkembang dari kalangan rumah tangga sampai industri yang berskala besar, termasuk perkembangan industri di bidang pengalengan ikan. Kesehatan pekerja merupakan salah satu hal yang penting dalam sebuah perusahaan, dapat tercapai dengan pemilihan metode kerja yang tepat. Penelitian ini dilakukan untuk mengetahui apakah metode kerja berorientasi ergonomi pada proses pengelapan kaleng sarden dapat menurunkan keluhan muskuloskeletal dan kelelahan pada pekerja. Rancangan penelitian adalah rancangan silang dua periode sama subjek. Penelitian dilaksanakan di PT.BMP yang terletak di Negara. Dilaksanakan pada bulan Desember 2016. Sampel berjumlah 18 orang pekerja pengelapan kaleng sarden. Perbedaan kondisi antara sebelum dan setelah kegiatan mengunakan metode kerja tidak berorientasi ergonomi dan metode kerja berorientasi ergonomi dibandingkan dan diuji secara statistik. Uji komparasi dilakukan terhadap skor keluhan muskuloskeletal dan kelelahan pekerja. Hasil penelitian menunjukkan bahwa metode kerja berorientasi ergonomi menyebabkan penurunan skor keluhan muskuloskeletal 17,82\% ( $<<0,05)$ dan penurunan skor kelelahan sebesar $11,86 \%(\mathrm{p}<0,05)$. Simpulan penelitian ini adalah metode kerja berorientasi ergonomi pada proses pengelapan kaleng sarden menurunkan keluhan muskuloskeletal dan kelelahan kerja pekerja di PT. BMP Negara.
\end{abstract}

Kata kunci: keluhan muskuloskeletal, kelelahan, metode ergonomi

\section{Ergonomic Oriented Working Method in The Process Of Wiping Cans Of Sardines Reducing Musculoskeletal Complaints and Fatigue Among Workers in PT. BMP Negara, Bali}

\begin{abstract}
Industrial activities developed from households to large-scale industries, including the development of industries in the field of canning fish. Worker health is one of the important things in a company, can be achieved by choosing the right work method. This study was conducted to determine whether ergonomic oriented working methods in the process of wiping canned sardines can reduce musculoskeletal complaints and fatigue in workers. The study design was two period cross over pre and post-test group desig). The research was conducted at PT. BMP Negara. It was held in December 2016. Total sample were 18 workers who wiping cans of sardines. The difference in conditions between before and after activities using ergonomic un-oriented working methods and ergonomic oriented working methods are compared and tested statistically. Comparison tests were
\end{abstract}


carried out on scores of musculoskeletal complaints and worker fatigue. The results showed that ergonomic oriented working methods decreased of musculoskeletal complaints $17.82 \%(p<0.05)$ and fatigue score of $11.86 \%$ ( $p<0.05)$. The conclusion of this study is that ergonomic oriented working methods in the process of wiping sardine cans reduce musculoskeletal complaints and work fatigue of workers in PT. BMP Negara.

Keywords: musculoskeletal complaints, fatigue, ergonomic method,

\section{PENDAHULUAN}

Berkembangnya industri di berbagai bidang pada saat ini merupakan bagian yang tidak terpisahkan dari kehidupan masyarakat. Kegiatan industri berkembang dari kalangan rumah tangga sampai industri yang berskala besar, termasuk perkembangan industri di bidang pengalengan ikan. Untuk dapat bertahan atau menjadi unggul dalam persaingan yang ada maka meningkatkan produktivitas perusahaan menjadi salah satu hal yang penting dilakukan oleh sebuah perusahaan.

PT. BMP merupakan suatu perusahaan yang bergerak dalam bidang industri makanan dalam kemasan (ikan dalam kaleng) dengan produk berupa sarden, mackerel dan tuna (PT. BMP, 2016). Pembuatan sarden terdiri atas beberapa proses, diawali dengan penerimaan bahan baku, penyimpanan, pemotongan, pencucian, pengisian kaleng, pengukusan, penirisan, pengisian saos, penutupan kaleng, pencucian kaleng isi, sterilisasi, isolasi, pengelapan, labeling dan pengemasan, penyimpanan, terakhir pengiriman (Manual HCCP PT. BMP, 2015)

Proses pengelapan dilakukan sebelum sarden dikemas ke dalam kardus, dengan tujuan agar kaleng sarden tidak kotor, berminyak ataupun berdebu. Setelah kaleng dalam kondisi bersih kemudian dilakukan proses pengemasan. Tiap kaleng sarden beratnya $25 \mathrm{~kg}$ dan dimasukkan ke dalam kardus dengan jumlah masing-masing kardus 24 buah kaleng. Pekerja pengelapan pada proses pengelapan kaleng sarden bekerja dengan sikap berdiri, dimana pekerjaan dimulai pukul 08.00 Wita hingga pukul 16.00 Wita dengan waktu istirahat selama satu jam pada pukul $12.00-13.00$ Wita.

Metode kerja pengelapan kaleng sarden yang diterapkan oleh pekerja di bagian pengelapan yaitu mengelap kaleng sarden sebanyak mungkin kemudian menumpuk secara acak. Setelah itu dimasukkan dan ditata ke dalam kardus. Metode kerja ini belum berorientasi ergonomi karena saat proses menata pekerja membutuhkan waktu yang lebih panjang untuk memposisikan kaleng agar komposisi seluruh kaleng dalam kardus tersusun sesuai dengan aturan. Dari studi pendahuluan terhadap 5 orang pekerja ditemukan bahwa pada saat pekerjaan pengelapan dilakukan dengan metode kerja tidak berorientasi ergonomi, pekerja merasakan keluhan muskuloskeletal terutama di bagian leher belakang, pundak, lengan atas, pergelangan tangan, pinggang dan betis. Keluhan diukur menggunakan kuesioner Nordic Body Map dan didapatkan rerata skor keluhan muskuloskeletal sebesar 76,6. Kelelahan pada pekerja juga diukur dengan kuesioner 30 Item of Rating Scale, didapatkan bahwa rerata skor kelelahan pekerja adalah 79,50. Hal ini kemungkinan disebabkan oleh posisi kerja berdiri dan jenis pekerjaan yang bersifat monoton.

Ketika permintaan konsumen terhadap sarden meningkat, pekerja diharapkan bekerja lembur dengan waktu yang bervariasi dua sampai tiga jam per hari. Kerja lembur yang dilakukan oleh pekerja akan mengakibatkan akumulasi kelelahan dan munculnya keluhan muskuloskeletal pada pekerja. Kelelahan kerja merupakan keadaan yang disertai dengan menurunnya efisiensi dan daya tahan tubuh dalam melakukan pekerjaan yang dapat disebabkan oleh proses kerja yang tidak baik. Kelelahan akan menyebabkan menurunnya perhatian pekerja, menurunnya tingkat kewaspadaan dalam bekerja sehingga dapat 
menyebabkan terjadinya kecelakaan kerja, tidak mampu berkonsentrasi secara baik dalam melakukan kegiatan yang berhubungan dengan mental dan fisik.

Perubahan faal tubuh dari kondisi segar menjadi letih akan mempengaruhi keoptimalan kinerja pekerja. Pemulihan kondisi faal tubuh untuk kembali pada kondisi segar selama beraktivitas merupakan hal penting yang perlu diperhatikan. Salah satu faktor yang dapat mempengaruhi pemulihan energi adalah istirahat. Apabila lamanya waktu istirahat tidak sesuai dengan beban kerja yang diberikan akan menyebabkan pekerja berada dalam kondisi yang tidak optimal atau lelah.

Metode kerja berorientasi ergonomi pada proses pengelapan kaleng sarden mampu menghemat waktu kerja sehingga keluhan muskuloskeletal dan kelelahan yang dirasakan pekerja lebih rendah dibandingkan metode kerja tidak berorientasi ergonomi. Kaleng sarden yang dilap oleh pekerja berbeda untuk sisi atas dan sisi bawah, ketika pekerja bekerja menggunakan metode kerja tidak berorientasi ergonomi, saat proses menata pekerja membutuhkan waktu yang lebih panjang untuk memposisikan kaleng agar komposisi seluruh kaleng dalam kardus tersusun sesuai dengan aturan perusahaan. Berbeda halnya dengan bekerja menggunakan metode kerja berorientasi ergonomi, saat proses mengelap kaleng sarden pekerja langsung menata kaleng ke dalam kardus dengan posisi kaleng bagian atas sesuai dengan aturan perusahaan, sehingga waktu kerja yang dibutuhkan lebih singkat.

Pemilihan metode kerja yang tepat dapat menyederhanakan pekerjaan yang dapat mempengaruhi keluhan selama bekerja seperti kelelahan, keluhan muskuloskeletal yang dialami oleh pekerja (Nibel, 1999). Maka dari itu perlu dilakukan penelitian dalam upaya mengatasi masalah yang muncul. Upaya pendekatan partisipasi dengan pekerja pengelapan sarden dan pihak perusahaan menunjukkan bahwa alternatif yang dipilih adalah membandingkan metode kerja pengelapan kaleng sarden. Upaya intervensi ini dipilih untuk mengetahui apakah metode kerja berorientasi ergonomi pada proses pengelapan kaleng sarden dapat menurunkan keluhan muskuloskeletal dan kelelahan pekerja di PT. BMP Negara.

\section{METODE}

Penelitian ini adalah penelitian eksperimental dengan menggunakan pendekatan silang atau two-period cross over design. Populasi target adalah para pekerja bagian pengelapan di Jembrana. Populasi terjangkau adalah para pekerja bagian pengelapan di PT. BMP yang berjumlah 30 orang. Teknik penentuan sampel untuk penelitian ini adalah menggunakan teknik pemilihan secara acak sederhana (simple random sampling) dengan metode undian. Jumlah sampel yang dibutuhkan adalah 9 orang. Total seluruh sampel berjumlah 18 orang.

Metode kerja merupakan cara kerja yang dilakukan oleh masing-masing pekerja pengelapan kaleng sarden. Metode kerja tidak berorientasi ergonomi merupakan metode kerja mengelap kaleng sarden sebanyak mungkin kemudian menumpuk secara acak, setelah itu dimasukkan dan ditata ke dalam kardus. Metode kerja berorientasi ergonomi merupakan metode kerja mengelap kaleng sarden satu persatu kemudian memasukkan dan ditata ke dalam kardus. Keluhan muskuloskeletal merupakan keluhan pada sistem otot rangka yang diakibatkan oleh faktor-faktor kerja dan lingkungan kerja yang didapat saat melakukan pekerjaan yang didata dengan menggunakan kuesioner Nordic Body Map dengan 4 skala Likert. Kelelahan merupakan rasa lelah yang dirasakan selama proses kerja oleh karena faktor-faktor kerja dan lingkungan kerja yang didata menggunakan kuesioner 30 Item of Rating Scale dengan 4 skala Likert. Hasil pada penelitian diolah dan dianalisis menggunakan komputer dengan program SPSS (Statistical Package for the Social Sciences). 


\section{HASIL DAN PEMBAHASAN}

Data karakteristik subjek penelitian dicatat meliputi umur, berat badan, tinggi badan, indeks massa tubuh (IMT) dan pengalaman kerja. Hasil pencatatan ditunjukkan pada Tabel 1.

Tabel 1.

Deskripsi karakteristik subjek penelitian

\begin{tabular}{clcc}
\hline No. & \multicolumn{1}{c}{ Variabel } & Rerata & Simpang Baku \\
\hline 1. & Umur (th) & 32,27 & 5,84 \\
2. & Berat badan $(\mathrm{kg})$ & 58,05 & 6,46 \\
3. & Tinggi Badan $(\mathrm{cm})$ & 154,89 & 3,96 \\
4. & IMT $\left(\mathrm{Kg} / \mathrm{m}^{2}\right)$ & 24,16 & 2,23 \\
5. & Pengalaman kerja (th) & 7,44 & 2,00 \\
\hline
\end{tabular}

Jika dilihat dari umur, berat badan, tinggi badan, dan IMT, karakteristik subjek seperti pada Tabel 1 termasuk dalam kategori normal sedangkan pengalaman kerja subjek termasuk dalam kategori berpengalaman. IMT normal orang Indonesia berkisar pada nilai $18,5-25$ $\mathrm{kg} / \mathrm{m}^{2}$ (Almatzier, 2001). IMT merupakan indikator status nutrisi, apabila IMT di bawah 18,5 $\mathrm{kg} / \mathrm{m}^{2}$ dikatakan sangat kurus (underweight) sedangkan diatas $25,0 \mathrm{~kg} / \mathrm{m}^{2}$ dikatakan obesitas (overweight) (Mei, dkk., 2002). Dengan berat badan ideal, pekerja dapat melakukan aktivitas secara optimal, terutama aktivitas fisik. Rerata pengalaman kerja subjek adalah $7,44 \pm 2,00$ tahun. Rerata pengalaman subjek menunjukkan bahwa subjek telah terampil dan mampu untuk beradaptasi dengan pekerjaannya. Pengalaman kerja mempunyai hubungan yang erat dalam aktivitas subjek untuk menyelesaikan pekerjaannya.

Sementara itu data karakteristik lingkungan kerja selama subjek beraktivitas menunjukkan rerata suhu kering pada Periode I $29,50 \pm 1,29^{\circ} \mathrm{C}$ dan pada Periode II $29,83 \pm 1,46^{\circ} \mathrm{C}$. Suhu basah pada Periode I dengan rerata $25,61 \pm 0,69^{\circ} \mathrm{C}$ dan Periode II dengan rerata $25,55 \pm 0,61^{\circ} \mathrm{C}$. Kondisi ini merupakan kondisi yang nyaman untuk melakukan pekerjaan, karena menurut Manuaba (2004), suhu nyaman untuk daerah tropis adalah antara $22^{\circ} \mathrm{C}$ s.d. $28^{\circ}$ C. Rerata kelembaban relatif pada Periode I adalah $86,84 \pm 2,98 \%$ dan pada Periode II rerata $85,74 \pm 3,10 \%$. Hal ini merupakan kondisi kurang nyaman untuk melakukan pekerjaan. Kondisi yang nyaman untuk melakukan pekerjaan, dimana kelembaban relatif untuk daerah tropis antara 70\% - 80\% (Manuaba, 2004).

Kecepatan angin pada Periode I dengan rerata $0,05 \pm 0,01 \mathrm{~m} / \mathrm{s}$ dan pada Periode II dengan rerata $0,04 \pm 0,01 \mathrm{~m} / \mathrm{s}$. Menurut Manuaba (2004) kecepatan angin di suatu ruangan memberikan pengaruh kepada suhu yang dirasakan seseorang. Kecepatan angin di dalam ruangan diharapkan tidak melebihi $0,2 \mathrm{~m} / \mathrm{s}$. Intensitas pencahayaan di lingkungan kerja

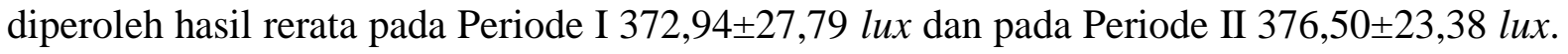
Sumber penerangan di tempat penelitian berasal dari sinar matahari (ventilasi udara) dan dari penerangan buatan (pemasangan lampu). Pencahayaan pada ruangan ini sudah memenuhi standar pencahayaan yang baik, karena standar pencahayaan yang baik adalah minimal 200 lux.

Keluhan muskuloskeletal dianalisis secara bertahap yang meliputi efek periode, efek residu, dan efek perlakuan. Analisis efek periode yang diukur dijelaskan seperti pada Tabel 2. Keluhan muskuloskeletal menunjukkan hasil tidak berbeda bermakna $(p>0,05)$ dengan rerata skor metode kerja tidak berorientasi ergonomi dan berorientasi ergonomi pada periode I adalah 13,22 $\pm 1,78$ dan rerata skor metode kerja tidak berorientasi ergonomi dan berorientasi ergonomi pada periode II adalah 13,92 $\pm 3,52$.

Tabel 2. 
Analisis efek periode keluhan muskuloskeletal

\begin{tabular}{ccccccc}
\hline Kelompok Subjek & $\mathrm{n}$ & Rerata & $\mathrm{SB}$ & $\begin{array}{c}\text { Beda } \\
\text { Rerata }\end{array}$ & $\mathrm{t}$ & $\mathrm{p}$ \\
\hline $\begin{array}{l}\text { Metode kerja tidak berorientasi ergonomi } \\
\text { dan berorientasi ergonomi pada periode I }\end{array}$ & 9 & 13,24 & 1,78 & & & \\
$\begin{array}{l}\text { Metode kerja tidak berorientasi ergonomi } \\
\text { dan berorientasi ergonomi pada periode II }\end{array}$ & 9 & 13,92 & 3,52 & 0,68 & 1,43 & 0,17 \\
\hline
\end{tabular}

Hasil analisis efek periode ini menunjukkan bahwa tidak ada efek periode penelitian terhadap keluhan muskuloskeletal, sehingga dapat disimpulkan bahwa penurunan skor keluhan muskuloskeletal semata-mata disebabkan oleh metode kerja yang digunakan pada proses pengelapan kaleng sarden. Tidak ada efek periode terhadap keluhan muskuloskeletal subjek, sehingga dapat disimpulkan penurunan skor keluhan muskuloskeletal semata-mata disebabkan oleh perlakuan yang diberikan.

Analisis efek residu seperti pada Tabel 3 menunjukkan rerata skor keluhan muskuloskeletal pada analisis efek residu, pada metode kerja tidak berorientasi ergonomi pada periode I dan II adalah 14,57 $\pm 3,06$, dan rerata skor keluhan muskuloskeletal pada

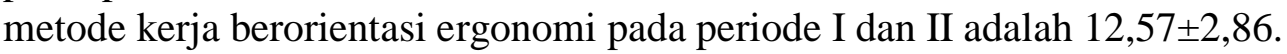

Tabel 3.

Analisis efek residu keluhan muskuloskeletal

\begin{tabular}{lcccccc}
\hline \multicolumn{1}{c}{ Kelompok Subjek } & $\mathrm{n}$ & Rerata & $\begin{array}{c}\text { Simpang } \\
\text { Baku }\end{array}$ & $\begin{array}{c}\text { Beda } \\
\text { Rerata }\end{array}$ & $\mathrm{t}$ & $\mathrm{p}$ \\
\hline $\begin{array}{l}\text { Metode kerja tidak berorientasi ergonomi } \\
\text { pada periode I dan II }\end{array}$ & 9 & 14,57 & 3,06 & & & \\
$\begin{array}{l}\text { Metode kerja berorientasi ergonomi pada } \\
\text { periode I dan II }\end{array}$ & 9 & 12,57 & 2,86 & 0,02 & 1,43 & 0,17 \\
\hline
\end{tabular}

Analisis efek residu menunjukkan tidak ada perbedaan bermakna ( $>0,05)$. Hal ini menunjukkan bahwa tidak ada sisa kegiatan pada periode I terhadap kegiatan pada periode II, sehingga dapat diasumsikan bahwa penurunan skor keluhan muskuloskeletal yang terjadi diakibatkan oleh penerapan metode kerja.

Tabel 4.

Analisis efek perlakuan keluhan muskuloskeletal

\begin{tabular}{|c|c|c|c|c|c|c|}
\hline Variabel & $\mathrm{n}$ & $\begin{array}{c}\text { Metode kerja } \\
\text { tidak } \\
\text { berorientasi } \\
\text { ergonomi }\end{array}$ & $\begin{array}{l}\text { Metode } \\
\text { kerja } \\
\text { berorientasi } \\
\text { ergonomi }\end{array}$ & $\begin{array}{l}\text { Beda } \\
\text { Rerata }\end{array}$ & $\mathrm{t}$ & $\mathrm{p}$ \\
\hline & & Rerata $\pm S B$ & Rerata \pm SB & & & \\
\hline $\begin{array}{l}\text { Keluhan muskuloskeletal } \\
\text { sebelum kerja }\end{array}$ & 18 & $34,25 \pm 1,85$ & $35,33 \pm 1,63$ & 0,22 & $-1,85$ & 0,07 \\
\hline $\begin{array}{l}\text { Keluhan muskuloskeletal } \\
\text { setelah kerja }\end{array}$ & 18 & $76,13 \pm 1,31$ & $62,56 \pm 2,41$ & 13,57 & $-3,72 *$ & 0,01 \\
\hline
\end{tabular}


Analisis efek residu terhadap keluhan muskuloskeletal subjek sebelum kerja untuk kedua metode kerja adalah komparabel, sehingga dapat diasumsikan bahwa penurunan skor keluhan muskuloskeletal semata-mata disebabkan metode kerja. Selanjutnya analisis skor keluhan muskuloskeletal setelah kerja menggunakan uji Wilcoxon didapatkan hasil berbeda bermakna $(\mathrm{p}<0,05)$ dengan nilai $\mathrm{p}=0,01$. Hasil tersebut digambarkan pada Tabel 4 .

Rerata skor keluhan muskuloskeletal sebelum kerja pada metode kerja tidak berorientasi ergonomi adalah 34,25 $\pm 1,85$ dan sebelum kerja pada metode kerja berorientasi ergonomi adalah 35,33 $\pm 1,63$. Dari hasil analisis didapatkan skor keluhan muskuloskeletal sebelum kegiatan antara metode kerja tidak berorientasi ergonomi dan metode kerja berorientasi ergonomi tidak berbeda bermakna ( $p>0,05)$.

Uji keluhan muskuloskeletal setelah kerja menunjukkan rerata skor keluhan muskuloskeletal setelah kegiatan pada metode kerja tidak berorientasi ergonomi adalah $76,13 \pm 1,31$ dan rerata skor keluhan muskuloskeletal pada metode kerja tidak berorientasi ergonomi adalah $62,56 \pm 2,41$. Skor keluhan muskuloskeletal tersebut menunjukkan terjadi penurunan skor keluhan muskuloskeletal sebesar 13,57 atau 17,82\%. Dari hasil uji beda kedua skor keluhan muskuloskeletal setelah kegiatan penelitian menunjukkan skor keluhan muskuloskeletal berbeda bermakna $(\mathrm{p}<0,05)$. Tabel 4 menunjukkan terdapat perbedaan yang signifikan pada subjek yang bekerja menggunakan metode kerja tidak berorientasi ergonomi dibandingkan dengan metode kerja berorientasi ergonomi.

Pekerja pengelapan kaleng sarden bekerja dengan sikap berdiri disertai dengan adanya gerakan repetitif. Sikap kerja yang tidak alamiah atau sikap paksa dan tidak efisien menyebabkan terjadinya reaksi berupa keluhan pada sistem otot skeletal (Manuaba, 1992). Penurunan keluhan muskuloskeletal pada penelitian ini terjadi karena perbedaan metode kerja pengelapan kaleng sarden yang dilakukan oleh pekerja antara Periode I dan II. Penggunaan metode kerja berorientasi ergonomi dengan tahapan kerja yang lebih singkat terbukti menghemat waktu kerja sehingga keluhan muskuloskeletal yang dirasakan pekerja lebih rendah dibandingkan metode kerja tidak berorientasi ergonomi.

Kaleng sarden yang dilap oleh pekerja berbeda untuk sisi atas dan sisi bawah, ketika pekerja bekerja menggunakan metode kerja tidak berorientasi ergonomi, saat proses menata pekerja membutuhkan waktu yang lebih untuk memposisikan kaleng agar komposisi seluruh kaleng dalam kardus tersusun sesuai dengan aturan perusahaan. Berbeda halnya dengan bekerja menggunakan metode kerja berorientasi ergonomi, setelah proses mengelap pekerja langsung menata kaleng ke dalam kardus, sehingga waktu kerja lebih singkat.

Penelitian yang dilakukan Adiatmika (2007) menyatakan bahwa perbaikan kondisi kerja dengan pendekatan ergonomi total dapat menurunkan keluhan muskuloskeletal sebesar $5,24 \%$ pada perajin pengecatan logam di Kediri Tabanan. Penelitian lain yang dilakukan Surata (2011) bahwa redesain alat dan sistem kerja menurunkan keluhan muskuloskeletal sebesar 56,15\%. Dengan demikian, dapat dikatakan bahwa metode kerja berorientasi ergonomi terbukti mengurangi keluhan muskuloskeletal pekerja pengelapan kaleng sarden.

Analisis efek periode digambarkan seperti pada Tabel 5, dimana analisis efek periode terhadap kelelahan menunjukkan hasil tidak berbeda bermakna $(\mathrm{p}>0,05)$ dengan rerata skor metode kerja tidak berorientasi ergonomi dan berorientasi ergonomi pada periode I adalah $8,24 \pm 1,57$ dan rerata skor metode kerja tidak berorientasi ergonomi dan berorientasi ergonomi pada periode II adalah $8,64 \pm 2,41$.

Tabel 5 menunjukkan bahwa tidak ada efek periode terhadap kelelahan pekerja, sehingga dapat diambil asumsi bahwa penurunan skor kelelahan semata-mata disebabkan oleh metode kerja yang digunakan pada proses pengelapan kaleng sarden. Tidak ada efek periode terhadap kelelahan pekerja, sehingga dapat disimpulkan penurunan skor kelelahan semata-mata disebabkan oleh perlakuan yang diberikan. 
Tabel 5.

Analisis efek periode kelelahan

\begin{tabular}{ccccccc}
\hline Kelompok Subjek & $\mathrm{n}$ & Rerata & $\mathrm{SB}$ & $\begin{array}{c}\text { Beda } \\
\text { Rerata }\end{array}$ & $\mathrm{t}$ & $\mathrm{p}$ \\
\hline $\begin{array}{l}\text { Metode kerja tidak berorientasi ergonomi } \\
\text { dan berorientasi ergonomi pada periode I }\end{array}$ & 9 & 8,24 & 1,57 & & & \\
$\begin{array}{l}\text { Metode kerja tidak berorientasi ergonomi } \\
\text { dan berorientasi ergonomi pada periode II }\end{array}$ & 9 & 8,64 & 2,41 & 0,84 & $-0,42$ & 0,68 \\
\hline
\end{tabular}

Analisis efek residu seperti pada Tabel 6 menunjukkan rerata skor kelelahan pada metode kerja tidak berorientasi ergonomi pada periode I dan II adalah $8,42 \pm 1,68$, dan rerata skor kelelahan pada metode kerja berorientasi ergonomi pada periode I dan II adalah $8,46 \pm 2,32$. Analisis efek residu menunjukkan tidak ada perbedaan bermakna ( $p>0,05)$. Hal ini menunjukkan tidak ada efek sisa kegiatan pada periode I terhadap kegiatan pada periode II, sehingga dapat diasumsikan bahwa penurunan skor kelelahan yang terjadi diakibatkan oleh penerapan metode kerja.

Tabel 6.

Analisis efek residu kelelahan

\begin{tabular}{lcccccc}
\hline \multicolumn{1}{c}{ Kelompok Subjek } & $\mathrm{n}$ & Rerata & $\mathrm{SB}$ & $\begin{array}{c}\text { Beda } \\
\text { Rerata }\end{array}$ & $\mathrm{t}$ & $\mathrm{p}$ \\
\hline $\begin{array}{l}\text { Metode kerja tidak berorientasi ergonomi } \\
\text { pada periode I dan II }\end{array}$ & 9 & 8,42 & 1,68 & & & \\
$\begin{array}{l}\text { Metode kerja berorientasi ergonomi pada } \\
\text { periode I dan II }\end{array}$ & 9 & 8.46 & 2,32 & 0,64 & $-0,41$ & 0,97 \\
\hline
\end{tabular}

Analisis efek perlakuan dilakukan dengan menganalisis kondisi sebelum bekerja, dimana kelelahan subjek sebelum kerja untuk kedua metode kerja adalah komparabel, sehingga dapat disimpulkan bahwa penurunan skor kelelahan semata-mata disebabkan oleh metode kerja yang diterapkan (Tabel 7). Selanjutnya analisis skor kelelahan setelah kerja menggunakan Paired $t$-test didapatkan hasil berbeda bermakna $(\mathrm{p}<0,05)$ dengan nilai $\mathrm{t}=18,04$ dan $\mathrm{p}=0,01$. Berarti metode kerja berorientasi ergonomi dapat menurunkan kelelahan pekerja.

Tabel 7.

Analisis efek perlakuan kelelahan

\begin{tabular}{|c|c|c|c|c|c|c|}
\hline Variabel & $\mathrm{n}$ & $\begin{array}{c}\text { Metode kerja } \\
\text { tidak } \\
\text { berorientasi } \\
\text { ergonomi }\end{array}$ & $\begin{array}{c}\text { Metode } \\
\text { kerja } \\
\text { berorientasi } \\
\text { ergonomi }\end{array}$ & $\begin{array}{l}\text { Beda } \\
\text { Rerata }\end{array}$ & $\mathrm{t}$ & $\mathrm{p}$ \\
\hline & & Rerata \pm SB & Rerata \pm SB & & & \\
\hline Kelelahan sebelum kerja & 18 & $34,62 \pm 1,81$ & $35,03 \pm 1,66$ & 0,41 & $-0,70$ & 0,48 \\
\hline Kelelahan setelah kerja & 18 & $71,24 \pm 0,64$ & $62,79 \pm 1,69$ & 8,45 & 18,04 & 0,01 \\
\hline
\end{tabular}

Rerata kelelahan sebelum kerja pada metode kerja tidak berorientasi ergonomi adalah $34,63 \pm 1,81$ dan sebelum kerja pada metode kerja berorientasi ergonomi adalah $35,04 \pm 1,66$, 
sehingga kondisi awal tidak berbeda bermakna ( $p>0,05)$. Rerata kelelahan setelah kerja pada metode kerja tidak berorientasi ergonomi adalah 71,24 $\pm 0,64$ dan rerata kelelahan pada metode kerja berorientasi ergonomi adalah $62,79 \pm 1,69$. Skor kelelahan tersebut menunjukkan terjadi penurunan skor kelelahan sebesar 8,45 atau $11,86 \%$. Dari hasil uji beda kedua skor kelelahan setelah kegiatan penelitian menunjukkan skor kelelahan berbeda bermakna $(\mathrm{p}<0,05)$.

Penurunan kelelahan ini terjadi karena perbedaan metode kerja pengelapan kaleng sarden yang dilakukan oleh pekerja antara Periode I dan II. Penggunaan metode kerja berorientasi ergonomi yang dilakukan pekerja terbukti menghemat waktu kerja sehingga kelelahan yang dirasakan pekerja lebih rendah dibandingkan metode kerja tidak berorientasi ergonomi. Kaleng sarden yang dilap oleh pekerja berbeda untuk sisi atas dan sisi bawah, ketika pekerja bekerja menggunakan metode kerja tidak berorientasi ergonomi, saat proses menata pekerja membutuhkan waktu yang lebih untuk memposisikan kaleng agar komposisi seluruh kaleng dalam kardus tersusun sesuai dengan aturan perusahaan. Berbeda halnya dengan bekerja menggunakan metode kerja berorientasi ergonomi, setelah proses mengelap pekerja langsung menata kaleng ke dalam kardus, sehingga waktu kerja lebih singkat. Saat bekerja menggunakan metode kerja tidak berorientasi ergonomi waktu yang dibutuhkan untuk mengelap 1 kaleng sarden sekitar 5,11 detik, sedangkan menggunakan metode kerja berorientasi ergonomi sekitar 3,86 detik.

Dilihat dari analisis waktu gerakan (time motion study) yang bertujuan untuk mengetahui gerakan efektif maupun gerakan tidak efektif saat proses kerja didapatkan data saat bekerja menggunakan metode kerja tidak berorientasi ergonomi pekerja melakukan gerakan tidak efektif sebanyak 5 kali per jam, sedangkan bekerja menggunakan metode kerja berorientasi ergonomi pekerja melakukan gerakan tidak efektif sebanyak 2 kali per jam. Gerakan-gerakan tidak efektif yang dimaksud berupa duduk disela-sela waktu kerja, menggaruk kepala, menyeka keringat, serta berbincang-bincang antar pekerja.

Penelitian yang dilakukan Artayasa (2008), dengan pendekatan ergonomi total dapat menurunkan kelelahan pekerja sebesar 53,97\%. Penelitian lain yang dilakukan Adiatmika (2007) yang mengatakan bahwa kondisi kerja dengan pendekatan ergonomi total dapat menurunkan kelelahan 6,79\%. Demikian juga pada penelitian model kerja berdasarkan kaedah ergonomi, mendapatkan hasil bahwa model kerja tersebut mampu menurunkan kelelahan hingga $17,71 \%$ (Rolles, dkk., 2009). Upaya penurunan kelelahan pada perajin atau pekerja melalui intervensi ergonomi sesuai dengan pendapat Kimberly (2011) yang menyatakan bahwa perlu adanya perubahan sistem kerja untuk mengurangi tingkat kelelahan pekerja. Hal serupa juga dinyatakan oleh Suardana (2012) bahwa pendekatan ergonomi dalam perancangan arsitektur (ergo-arsitektur) meningkatkan kinerja dilihat dari penurunan kelelahan penggunanya.

\section{SIMPULAN}

Dapat disimpulkan bahwa metode kerja berorientasi ergonomi pada proses pengelapan kaleng sarden menurunkan keluhan muskuloskeletal pekerja sebesar 17,82\%. Metode kerja berorientasi ergonomi pada proses pengelapan kaleng sarden menurunkan kelelahan pekerja sebesar $11,86 \%$.

\section{DAFTAR PUSTAKA}

Adiatmika, I.P.G. 2007. "Perbaikan Kondisi Kerja Dengan Pendekatan Ergonomi Total Menurunkan Keluhan Muskuloskeletal dan Kelelahan Serta Meningkatkan 
Produktivitas Perajin Pengecat Logam di Kediri-Tabanan" (disertasi). Denpasar: Program Pascasarjana Universitas Udayana.

Almatzier, S. 2001. Prinsip dasar Ilmu Gizi. Jakarta: PT. Gramedia Pustaka Utama.

Artayasa, I N., Adiputra, N. dan Manuaba, A. 2008. Pendekatan Ergonomi Total Meningkatkan Kualitas Hidup Pekerja Wanita Pengangkut Kelapa di Banjar Semaja Antosari Selemadeg Tabanan Bali. Indonesian. Journal of Biomedical Sciences, Vol.2(2).

Bali Maya Permai. 2015. Manual Hazard Analysis and Critical Control Point. Negara

Bali Maya Permai. 2016. Profil Bali Maya.Negara. (cited 2016 May 04). Available From: http://www.bmpfood.com

Kimberly, F.K.2011. Pengaruh Shif Kerja Terhadap Kelelahan Pekerja Pabrik Kelapa Sawit Di PT. X Labuan Batu. Jurnal Teknik Industri, Vol. 12(2):110-117.

Manuaba, A. 1992. Pengaruh Ergonomi Terhadap Produktivitas Tenaga Kerja. Disampaikan Pada Seminar Produktivitas Tenaga Kerja. Jakarta, 30 Januari.

Manuaba, A. 2004. Kontribusi Ergonomi dalam Pembangunan, dengan Acuan Khusus Bali. Presented at the $2^{\text {nd }}$ National Seminar on Ergonomics. Yogyakarta, 9 Oktober.

Nibel, B. dan Freivalds, A. 1999. Method, Standar, and Work Design. McGraw-Hill. USA.

Rolles P., Manuaba, A., Adiputra, N., Pangkahila, A. 2009. Model Aktivitas Praktikum Lapangan Berbasis Ergonomi (Apelerg) Memperbaiki Respon Fisiologis Tubuh, Menurunkan Kelelahan, Dan Meningkatkan Kinerja, Dibandingkan Dengan Model Lama (Apel), Pada Mahasiswa FMIPA Unima. Indonesian Journal of Biomedical Sciences, Vol. 3(1).

Suardana, P.G.E. 2012. "Pendekatan Ergonomi Dalam Perancangan Arsitektur (ErgoArsitektur) Meningkatkan Kenyamanan dan Kinerja Pengguna" (disertasi). Denpasar: Program Pascasarjana Universitas Udayana.

Surata, I W. 2011. "Redesain Alat Pengering dan Sistem Kerja Meningkatkan Kinerja Petani dan Mutu Rumput Laut di Desa Ped Nusa Penida" (disertasi). Denpasar: Program Pascasarjana Universitas Udayana. 